\title{
Physiotherapy for Children with Cerebral Palsy
}

\author{
Mintaze Kerem Günel \\ Hacettepe University, Faculty of Health Sciences, \\ Department of Physiotherapy and Rehabilitation, \\ Turkey
}

\section{Introduction}

Pediatric rehabilitation is defined to attain the independence level of children as functionally and psychologically, in the physiological, anatomic and environmental restrictions and to increase the quality of life of the children and their family (Olney et al., 2000). The rehabilitation process requires a multidisciplinary approach. In this process, inter and intra disciplinary communications are a necessity and the role of every discipline should be actualized according to the needs of the children and the family concurrently (Johnson et al., 2001, Kwolek, et al., 2001). Physiotherapists play a key role in the team of healthcare professionals dealing with children with disability. As the 'movement expert' on the team, their main aim is to help the children achieve their potential for physical independence and fitness levels, working closely with the person - and, in the case of children and young people - their parents or caretakers. As a child grows older, the physiotherapist will advise them and their parents or caretakers on independent skills and lifestyle, enabling the young person to take on increasing responsibility in meeting challenges in education, at leisure and at home. When a young person is transferred to adult services, the physiotherapist will continue to work with him/her to solve problems (Mohay, 1996, Kerem Gunel, 2009).

\section{Cerebral palsy}

Cerebral palsy (CP) describes a group of permanent disorders of the development of movement and posture, causing activity limitation, that are attributed to non-progressive disturbances that occurred in the developing fetal or infant brain (Bax et al., 2005). The motor disorders of $\mathrm{CP}$ are often accompanied by disturbances of sensation, perception, cognition, communication, and behaviour, with epilepsy, and with secondary musculoskeletal problems (Rosenbaum, 2007). The estimated prevalence in the general population is 2/1000 (Odding et al., 2006).). The limitations in activity require individual rehabilitation throughout life (Shepherd, 1995). The impaired control and coordination of voluntary muscles is accompanied by mental retardation or learning disabilities in 50 to $75 \%$ of children and by disorders of speech (25\%), auditory impairments (25\%), seizure disorders (25-35\%), or abnormalities of vision (40-50\%) (Schanzenbacher, 1989).

Damage, which the central nervous system (CNS) of the children with CP cause, are disorders in neuromuscular, musculoskeletal and sensorial systems (Butler, 1999). These disorders bring posture and movement deficiencies. Functional independence levels of these children are affected negatively due to secondary disorders such as various musculoskeletal 
deformations and third disorders due to different compensation mechanisms during the time. Although the damage is not progressive, results of deficiency and disability may be progressive (Butler, 2001).

The main problem in all types of $\mathrm{CP}$ is motor disorders accompanying with sensorial and cognitive problems (Tirosh \& Rabino, 1989). The causes of motor disorders are; developmental retardation, abnormal muscle tone, muscle weakness, postural control deficiencies, sensorial problems, behavioural problems, orthopaedic problems, abnormal movement patterns and reflex activity, asymmetry and deformities (Styer-Acevedo , 1999). The functions that a child with CP should gain by following motor developmental milestones are delayed related to the severity of lesion. Presence of primitive reflexes which should be inhibited in the normal developmental process avoids correction and equilibrium reactions to develop (Papavasiliou, 2009).

The lesion, which is formed in CNS of a child with CP affects the proper functioning of the normal postural control mechanism. The alterations of tonus (spasticity, rigidity, dystonia) instead of normal postural tonus occurs in the form of reciprocal innervation deficiency, abnormal posture and abnormal coordination patterns, insufficient normal fixation and abnormal fixation during motion (Deon \& Gaebler-Spira, 2010). Alterations in motion and posture control depend on the harmonious relation between the gravity centre of the body and the support surface. An orderly and sufficient amount of contraction should be present in muscles so as to ensure coordinated movement during a function and ensure balance. Such tonus adaptations in the muscles are automatically formed as continuous and dynamic patterns (Harris \& Roxborough, 2005). Muscular tonus needs to create sufficient muscular power for resisting the gravity of the muscular tonus so that the proper posture and postural control can be achieved in children, thus desired motion can be ensured in a controlled way (de Graaf-Peters et al., 2007).

One of the main reasons in decreasing functional skill in CP is the abnormalities in muscular tonus. Such abnormalities may take place in the form of hypertonus, hypotonus or muscular fluctuation. The most frequently encountered tonus disorder is spasticity. Spasticity is a clinical table that is characterized with a speed-dependent increase in increased tendon reflex and straining reflex as a component of upper motor neuron lesion. Hypotonia is generally early infantry-specific. Mostly, it develops into spasticity, rigidity or muscular fluctuation in later periods (Krägeloh-Mann \& Cans, 2009). Particularly the children already hypotonic at the onset need to be considered in this respect. Hypotonia, which results from deficiency within the facilitator control or cerebellum, may be more permanent in ataxic type. Tonus alteration may be observed over time in a child with $\mathrm{CP}$, as well as various tonus disorders in various body parts in children with CP. Hypotonia may be formed in the body when there is hypotonia in extremities. Muscular tonus disorders may vary according to the general condition of the child, environmental stimuli, the force and speed of the strain imposed in the muscle (Damiano \& Moreau, 2008). Hypertonia and deficiency of reciprocal innervation in children with $\mathrm{CP}$, which is confronted by the increase in co-contractions explains the decrease in the motions. However, in ataxic and athetoid children, there is a decrease in co-contraction and reciprocal inhibition. Fixation skill has been decreased and an apparent deficiency has occurred in postural control due to co-contraction combined with over-mobility. Therefore, deficiency of control, balance and coordination is observed in dyskinetic children (Stanley\& Blair, 2000). 
Muscular weakness is a secondary development to abnormal tonus problems. Bertha and Karel Bobath have emphasized the importance of considering this situation among children with neurological disorder and have noted that muscular weakness may cause a problem when hypertonus is decreased. Also mobility inability or hypo-mobility among children with $\mathrm{CP}$ may cause atrophy and muscular weakness. On the other hand, muscle fails to show the existing force potential due to the deficiency in selective muscular contraction and deteriorated co-contraction mechanism. A loss may occur in the control over motor neuron pools of the spinal cord of the upper motor centres due to CNS lesion, as well, and muscular activation deficiency may occur during motion due to neurophysiologic mechanism (Bobath \& Bobath, 1984).

Therefore, it is very important to increase muscular force in physiotherapy practices both for improving the function and controlling spasticity. On the other hand, it has been recently emphasized that spastic muscles were not strong, contrary to what is known, and the force of such muscles should also be assessed for the development of the functional mobility skill (Damiano et al., 2006).

While motor development retardation is considered to be the most important problem, it should also be considered that the sense integrity could also be affected. However, the motor development and sensory response after a CNS lesion are generally both affected and this effect causes developmental problems in children with CP. The long-term existence of primitive reflexes that occur during development, hypotonia, hypertonia or dystonia in muscles and muscle weaknesses that frequently accompanies may negatively affect sensory motor development negatively (O'Shea 2008). Limitation of motor capabilities and movement in children with CP negatively affects the development of the perception ability and reflects negatively on cognitive development. Children learn movements by using their senses and use the movements which they are experienced in. Children with $\mathrm{CP}$, however, gain experience in abnormal movements with repetition and usage and when they want to increase their movement ability they develop new abnormal actions. This also causes asymmetric posture and inability in controlling actions in children with $\mathrm{CP}$. Usage of normal sensory functions during abnormal movements is insufficient because the sensorymotor experience prevalent in children with $\mathrm{CP}$. Regular sensory patterns are formed during the first years of normal children and while this enables them to do more complicated and difficult activities in the future, this balance cannot be created in children with CP. The abnormal motor patterns, undeveloped posture and abnormal tonus also negatively affect the child's physical development (Mayston, 2001, Hadders-Algra, 2001).

Sensory problems that can cause hypo-mobility, posture problems and hypo-function need to be well assessed. Proprioception, vestibular, tactile, visual and hearing senses are senses that create significant input in creating voluntary movements. While the role of voluntary control is on the foreground it is shaped by responses given to warnings of surroundings. Thus, sensory problems that accompany in children with $\mathrm{CP}$ negatively affect the development of movement and function (Gunel, 2006).

Various factors in children with CP constitute a foundation, on which for deformities to form, in time. Dynamic deformities, that comprise soft tissue at first, lead to structural defects in the articulars and bones with time and cause the deformity to become static (Akbayrak et al., 2005). It is important to know what factors lead to preventing and decreasing the formation of deformity and applying physiotherapy approaches in this context is important. Factors that cause formation of deformity can, in general, be listed as immobility, hypertonus, hypotonus, co-contractions and synergy patterns, muscle weaknesses, abnormal reflex movements, asymmetry, involuntary and repetitive movement 
patterns, physical growth and biomechanical factors. Various sensory disorders accompanying in this table besides muscle weakness, tonus and posture defects, abnormal reflex and movement patterns create a platform for on which immobility, and as a result various contracture and deformities, to occur in children with $\mathrm{CP}$. In children with widespread hypotonia, various deformities can occur generally due to muscle weaknesses and disorders in the postural control mechanism. Deformities such as scoliosis, increased lordosis and kyphosis, flexion in the thigh, valgus and hyperextension in the knees and valgus in the feet can occur frequently in these children. Hypotonus limits the movement of the articulars and also puts weakness in the antagonist muscles in the table by terms of abnormal positions of the articulars while resting and abnormal movement patterns during voluntary movements, thus being one of the most important reasons that cause deformity. With this aspect, spasticity initiates an irreversible chain of events in the muscles, ligaments, articulars and bones (Novacheck \& Gage, 2007).

While the spastic muscles cause functional inability at first, it causes deformation with time. Deformities, in children with $\mathrm{CP}$, caused in connection with muscle contracture should be examined under two different headings; dynamic and static. Dynamic deformity means that the contracture is affiliated with spasticity and that it does not cause any difference in the articular. The muscle tendon unit enables the articulars to passively move in agonist and antagonist directions. In the case of static deformity, however, the passive movement of the affected segment of the extremity is not possible or it is seriously limited. It is very important to support the child's functional development in order to prevent and minimize the formation of deformity. To this end, the main targets are to ensure mobility, prevent asymmetric posture and give a proper stand posture, develop normal postural mechanisms and balance reactions, ensure biomechanical normality, control involuntary movements and decrease hypertonus (Gaebler-Spira \& Revivo, 2007).

Various problems of the musculoskeletal system causes various walking disorders in children with CP. Gage listed the factors that cause walking disorders in children with $\mathrm{CP}$ as loss in selective muscle control, existence of primitive reflex patterns, abnormal muscle tonus, imbalance between agonist and antagonist muscles and inability of balance reactions. Independent walking, which is generally delayed in children with $\mathrm{CP}$, also brings about various walking disorders. Different walking disorders may occur in context with the severity of influence, dispersion and clinical characteristics. These disorders have some characteristics typical to the clinical type of children (Novacheck et al., 2010).

\section{Assessment}

In an assessment of a child, whose physiotherapy and rehabilitation needs were determined and then was sent to a physiotherapist, answers of questions such as "Why is physiotherapy required?", "What are the active neurophysiologic and biomechanical mechanisms?", "How do the accompanying problems effect the situation?" should be searched. The clinical type, severity of the disease, chronologic age, age of initiating physiotherapy, existence and severity of abnormal reflexes, cognitive problems appearing together, hearing disorders, visual impairment, sensory-perception problems, general state of health and the sociocultural and economic status of the family should be considered while deciding on suitable physiotherapy methods (Stanger \& Oresic, 2003). The actual question that needs to be answered within scope of the information obtained, as a result of the assessment, is what is important in the child's life. What needs to be provided is not only motor development abilities such as sitting, crawling, walking, muscle tonus regulation, balance and 
coordination training. The acquisitions shall be ensured to be able to be used in daily life (Bower \& McLellan, 1992).

While clinical observation is one of the most important parts of the assessment, it completes standardized tests and contributes information which carries at least the same significance. By assessing the child, according to the parameters listed below, the physiotherapist shall present a general table of the child. The child must be calm and trust the physiotherapist during the observations conducted in terms of motor, sensory, cognitive, emotional and social/family. The mother, father or the guardian undertaking the care of the child shall be with the physiotherapist during the observation. The child must not be hungry, nor should be observed right after eating. The room where the observation will be done should be quiet, at an agreeable temperature and not contain unnecessary toys and equipment; if possible it should be a room covered with material that is appropriate for the child to move on the ground, with walls painted in warm colours and should not be too small. Firstly, what the child can do on his/her own should be observed while examining the functional movements, fine and gross motor skills during the observation (Mayston, 2008).

Within the scope of the assessment to be performed in terms of motor, besides the changes in the muscle tonus, co-contraction capacities of the muscles, involuntary extremity and body movements, stabilisation of the extremities, correction, balance and protective reactions, sitting balance, upper extremity and hand functions and sensory-perception problems; orthosis, need of mobilisation tools and other aid tools, cooperation of the family and their knowledge on the disease also needs to be assessed. The assessment of the motor function should be based on the normal process of a normal motor function development but it should also be sensitive towards special problems. For motor development reflex development, proper posture, sufficient extremity movements, appropriate muscle tonus, sensory development and cognitive functions within an integral neurologic and musculoskeletal system is required. Full completion of the motor development is required for the functional independence and social and emotional development of the child. Therefore it is required to know the normal development of a child. By knowing the normal development, the developmental problems that may occur in the child due to any reason can be better understood (Tsorlakis, 2004).

The methods used for assessing spasticity take place within a wide range that extends from clinical scales to more complex systems based on Electromyographic Analysis (EMG). Collecting comprehensive history and observations are very important in assessing the effect of spasticity on functions. The muscle groups, in which the spasticity exists, and their interaction with postural reactions' effect on functions should be researched. Although assessing functional activities and daily-life activities does not directly determine the severity of spasticity, it could present an idea on the reflection of the changes of the spasticity on the functional condition. One method of assessing spasticity in the clinic is to determine the amount of resistance that the spastic muscle presents during a passive movement of the relevant extremity. Ashworth has, accordingly, defined a 5-point scale. This scale evaluates the resistance that occurs during the passive movements of the extremities with points between 0-4. Although the Modified Ashworth Scale (MAS) is a subjective method in our day, it is widely used as an easily applied method that does not require any tool in assessing spasticity. The Tardieu Scale is another scale that assesses spasticity with passive movements, as does the AS and MAS. This scale presents spasticity's nature that depends on speed. Passive straining is performed at the speed of the extremity segments falling with gravity and slower and faster than this speed. The Modified Tardieu 
Scale (MTS) has added the assessment positions and spasticity angles of the extremities to the original scale. The MAS, Pendulum test and MTS for measuring the spasticity of children with CP was compared and MTS was determined to be most appropriate measurement method (Mutlu et al., 2007).

Spastic muscles limit articular movements in antagonist directions. Therefore, in addition to assessing the movement of the articular with a goniometre can also be used as an objective method although it presents conflicting results in terms of reliability. Assessments, which are not widely used in the clinic and are used more in assessments researches, are methods such as the dynamic flexometre, pendulum test, electrophysiologically assessing the $\mathrm{H}$ reflex and $\mathrm{M}$ response and the biomechanical analysis of response of the spastic muscle to angular and speed differences, etc. (Mutlu et al., 2008).

The Barry Albright dystonia scale is a highly reliable rating scale developed in order to asses the dystonia in patients with $\mathrm{CP}$ and traumatic brain injuries. The scoring is "none"; 0 , "slight"; 1, "mild"; 2, "moderate"; 3, and "severe";4. Each region has specific descriptors for a scoring. Generally if dystonia is present less than $10 \%$ of the time it is "slight", if it does not interfere with function or care it is "mild", if it makes functional movements harder it is "moderate", and if it prevents function it is "severe" (Albright, 1996).

The changes in the muscle tonus must include the contraction capacity of the muscles, involuntary extremity and trunk movements, the stability of the trunk and extremities, correction and balance reactions, sitting balance, upper extremity and hand functions, sensory-perception problems, speech and tongue functions and dietary status. Orthosis, mobilisation and other adaption devices, the general health condition of the child and the family's socio-cultural and economical conditions should also be assessed. Various tests and batteries should be used in order to assess different parameters such as the motor and reflex development level, muscle strength, normal articular movement, functional skills, and independence level and self-care activities (Anttila, 2008).

The most widely-used test battery that measures the functional motor level in order to determine the motor development level of children with $\mathrm{CP}$ is the Gross Motor Function Measurement (GMFM). With GMFM, physiotherapists can define the motor function level of the child; obtain aid in specifying the targets of the treatment, follow-up the posttreatment development and present objective information regarding the child to relevant colleagues, other inter-discipliner professionals and families. It was developed in 1989 by Russell et al. by considering the motor function level of a 5-year old child with normal motor development. The GMFM measures how much of the action is achieved rather than measure the quality of the motor performance. The purpose is to determine the capacity and change. It is comprised of sections of supine-facedown positions and turning, sitting, crawling and standing on knees, standing on feet, walking and running and jumping (Russell, 1989). The Gross Motor Function Classification System (GMFCS) is a classification system developed for children with CP. The GMFCS has been developed by Palasino et al. based on the actions the child can perform from sitting to walking. It is a practical system that can be used in clinics for the rehabilitation team to classify a child with $\mathrm{CP}$, observe the efficiency of the applications and follow-up on the patient in inter-intra discipliner applications. Initially, children with $\mathrm{CP}$ aged below 12 were divided into five levels by considering their independency in gross motor functions such as sitting, walking, mobilisation and transfer activities and the tools-equipment, tools that assist in walking that they use. As motor functions of children differ according to age, functions have been defined as under 2-years old, between 2-4 years old, between 4-6 years old and between 6-12 
years old for each level. This system was extended in order to include the age ranges of between 12-15 and 15-18 years old in 2007. The Manual Ability Classification System (MACS) is a system developed in 2003 by Ellioson et al. in order to classify the ability to hold objects with hands during daily activities of children with CP between the ages of 4-18. MACS aims to specify which level represents best the child's normal activities at school, home and in society. The MACS classification should be specified based on the real performance of the child in daily life. This should not be done by performing a special assessment, but by asking a person who knows the child and how he/she generally achieves these. While specifying the MACS level, it should be kept in mind that the child's ability of holding objects is related to age. The MACS assesses the participation of both hands in an activity and cannot separately asses the hand functions. The aim of the MACS is to provide a systematic method regarding classifying how children with $\mathrm{CP}$ use their hands while holding objects during daily activities. MACS, focuses on manual abilities that are initiated by the person itself and especially on holding the objects surrounding them. The MACS has defined 5 levels. The differences between each level also help to specify the level which has the closest similarity to the child's manual abilities (Palisano et al., 1997, Eliasson et al., 2007, Gunel , 2009).

The Functional Independence Measure for Children= WeeFIM has been developed by using the Functional Independence Measure (FIM) developed for adults by "Uniform Data System" in 2003. It is a useful, short, comprehensive measurement method that determines the development, educational and social functional limitations of children that have $\mathrm{CP}$ and other development disorders. WeeFIM contains a total of 18 articles in 6 fields; self-care, sphincter control, transfers, locomotion, communication, and social and cognitive. Whether or not the child is aided, performs on time or if they required an aiding device while performing the function in each article of these fields is scored from 1 to 7.1 point is given if they perform the mission with aid, 2 for independently performing, and 7 if they perform on the right time and safely. Accordingly, the child can score 18 the least (fully dependant) and 126 the most (fully independent) (Ottenbacher et al., 1999).

The Pediatric Evaluation Disability Inventory (PEDI), is a comprehensive clinical assessment tool that assesses the functional ability and performance of disabled children. It has been developed especially to asses the function of small children and is a distinguishing measurement method that can be used for children below 7,5 years old and also older children. PEDI, is comprised of three main sub-sections; functional abilities, help of caretakers and modifications. Each of these sections assesses self-care, mobility and social function areas. The functional abilities part comprises of 197 articles and measures the functional abilities of the child. In this section the "self-care" sub-section comprises of 73, the "mobility" sub-section comprises of 59 and the "social functions" sub-section comprises of 65 articles. The section regarding help of the caretakers comprises of 20 articles and measures the disability condition of the child according to the amount of aid required in order to perform the functional activity. The modifications section also comprises of 20 articles and shows the environmental modifications and tools that the child uses during his/her daily life. Each sub-section of PEDI can be used independently (Vos-Vromans et al., 2005).

Health-related quality of life (HRQL) is defined by the World Health Organisation Quality of Life Group as "an individual's perception of their position of life in the context of the culture and value systems in which they live and in relation to their goals, expectations, standards, and concerns". The International Classification System (ICF) notes that the HQRL 
should be taken into consideration in the assessments. Health-related quality of life should be considered in children with $\mathrm{CP}$ by terms of the child and the family. HRQL assessment in children with $\mathrm{CP}$, should mostly contain physical symptoms, activity limitations, emotional stress, communication problems between the child-family, limitation of school life and difficulties experienced in the treatment of the disease. Due to the $\mathrm{CP}$ chart of children with $\mathrm{CP}$, pain, general health, physical functions, actions with family are HRQL parameters. In comparison to normal children, as a result of $\mathrm{CP}$, decrease of independency at a functional level, difficulty in daily life activities, and cognitive and sensory problems that may accompany negatively affect the HRQL in children with $\mathrm{CP}$. Cognitive levels and speech functions are significant while determining the HRQL of children under 18. Therefore, surveys that measure the family's influence from the child with $\mathrm{CP}$ are widely used while determining the child's HRQL. It is required to develop quality of life questionnaires that comprise of questions that children that do not have cognitive problems can answer on their own. When literature is examined, we see that while assessing the HRQL of children with $\mathrm{CP}$, Paediatric Outcomes Data Collection Instrument (PODCI) and Child Health Questionnaire (CHQ) are used the most. The Child Health Questionnaire-Parent Form (CHQ-PF50); is an assessment method developed to assess the HQRL of children aged between 5 and 18 (Erdoganoglu \& Gunel, 2008).

Besides motor function problems being the main problem, when sensory, cognitive and mental problems accompany, the families' and caretakers', who have to take care of the children with $\mathrm{CP}$, whose daily life functions and independencies are affected, all day for many years, are also affected in physical and psycho-social terms. In terms of physical and psychosocial health, the child with $\mathrm{CP}^{\prime}$ s general health, the parent's own psychological structure, social support and distribution of roles within the family are influential in the family's HRQL. General health profiles and tests that measure HRQL are mostly used for measuring the influence on families with children with CP (Erdoganoglu \& Gunel, 2008).

\section{Classification}

$\mathrm{CP}$ is classified in various ways. These classifications can be grouped under various titles according to the body parts that are affected (topographic), the clinical type according to the prioritised motor findings, severity of influence and the causing pathology. In our day, the classification performed according to clinical characteristics is used the most. Classifications performed according to extremity distribution and severity take second place (Bax, 2005, Berger, 1998).

Classification according to clinical findings; is grouped under four headings: spastic, dyskinetic, ataxic and hypotonic. Most of the children with $\mathrm{CP}$ are of the spastic type; the ratio is approximately $70 \%$. It is stated that the dyskinetic type occurs at ratios of $20 \%$ and the ataxic type at $10 \%$. Some of these clinical types, especially spastic and diskinetic charts, can occur together and this is named as a mix type. Spasticity is observed in pyramidal system lesions, and extra pyramidal system involvements cause athetosis, chorea athetosis, dystonia, tremor and rigidity. Disorders in the cerebellum and the related systems, however, is clinically characterised by an ataxia (Aicardi \& Bax, 1998).

The spastic type, characterised by the increase of muscle tonus, constitutes the most frequently occurring clinical chart. The muscles that are most affected by spasticity are on the upper extremity; the shoulder extensor, retractor, adductor and internal rotators, elbow flexors, forearm pronators, wrists and finger flexors. On the lower extremity; hip flexor, 
adductor and internal rotators, knee flexors, ankle plantar flexors, and are sometimes evertors and sometimes invertors. Secondary weakness, various contracture and deformities and posture disorders frequently occur in the antagonists of these muscles. The periventricular leukomalacia that hold the medial fibrils of the corticospinal tract, more often cause a spastic diplegia table, while selective neuron necrosis in the cerebral cortex, parasagittal cerebral injury and intraventricular haemorrhage cause spastic hemiparesis and spastic quadriparesis tables. Besides spasticity, the suprasegmental reflexes controlled on brain stem level increases, thus, the tonic neck and labyrinth reflexes that are usually repressed are activated. While the lesion in the immature brain prevents the primitive reflexes from disappearing, the protective extensor reaction, corrective and balance reactions, which is required for motor development, postural control and ambulation and to continue during all of one's life, is delayed or obstructed. Apart from severe spastic events, it is difficult to understand spasticity in the first 4-6 months. After these months, the legs being in an extension, the shoulder being in a retraction and elbows being in a flexion position while supine, defines the table. In a facedown position, however, the tonic labyrinth reflex is dominant and the extremities are in a flexion position (Graham, 2001).

Dyskinesia caused by lesion affecting basal ganglions, is a clinical table in which involuntary and uncontrollable movements are in the foreground and can occur with various indications.

Chorea: Sudden, quick, aimless, dancing movements of the head, neck and extremities.

Athetosis: Involuntary, slow and snake-like movements. The plane, direction and timing of movements of the proximal articulars have mostly been defected. Chorea and athetosis sometimes occur at once, this is called choreoathetosis.

Ballismus: Involuntary thrusts like explosions. It is rare.

Tremor: Involuntary, rhythmic reciprocal, acute movements that occur due to the contraction of agonists and antagonists. These movements are generally more prominent in small articulars and extremity distal. It is rarely seen alone and is frequently accompanied by athetosis or ataxia.

Rigidity: Increase of tonus that includes both gravity and antigravity muscles (lead pipe and cogwheel indication).

Dystonia: Movements that are mostly characterised by constant muscle contractions in the trunk, neck and extremity proximal, causes contortions, repetitive movements or abnormal posture.

Diskinetic movements may occur in different ways. As it can occur as intermittent spasms characterised by increase in the flexor or extensor tonus due to tonic labyrinth and reflexes that affect the neck, it can also occur as mobile spasms that include the alternative flexion of extremities, extension, pronation and supination. Exaggerated movements, called momentary localized contractions, may occur with the muscle or muscle groups of anywhere in the body also being affected. Facial grimacing, exaggerated and asymmetric activation of the mimic muscles, rotating, bending movements of the hand and fingers, etc. Ataxic type; the ataxic table, developed as a result of selective neuron necrosis in the cerebellum, is characterised by disorder of teh kinaesthetic sense and balance and in-coordination. Before the child starts to walk, the first indication is hypotonia. Muscle weakness, rebound phenomenon, dynamic tremor, explosive speech, nystagmus, mental inability and astereognosis accompany in the table after the child starts to walk. Loss of balance is the distinctive characteristic of ataxia. The ataxia becomes more distinct when the child starts to walk. These children generally start walking late and their walking surface is wide while they sway while walking. 
Important problems encountered in children with ataxic $C P$ can be listed as hypotonia, occasionally increased muscle tonus, weak co-contraction, inability in postural stabilisation, dysmetria and coordination disorder in movements

Hypotonic Type

There is no normal, sufficient contraction and relaxation of the muscle. No involuntary movement occurs. It is mostly a transition stage in the development of athetosis or spasticity. It presents itself with decreased muscle tonus while at rest, decreased stretching reflex and decrease in primitive reflex patterns. In hypotonic children, decrease against passive movements, difficulty in lifting head while in facedown position, excessive flexibility in articulars especially in the ankle and wrist, weakness of the Moro and suction reflex are distinctive findings during the early phase.

Mixed Type

It is the combination of neuromuscular disorders and can occur with spasticity, dystonia and athetoid. Another classification is done according to the extremities that are affected.

Diparesis: It is a spastic CP in which mostly the lower extremities and some of the upper extremities are stiffened. It is clinically characterised distinct spasticity in the pelvis and lower extremities and moderate spasticity in the upper extremities and in-coordination.

Quadriparesis: Also named tetraparesis. It is the stiffening of the four extremities. The frequently dominant table is spasticity. In mix types, athetoid movements can be distinctive in the upper extremities while spasticity is distinctive in the lower. The severity between the right and left half of the body is differs.

Hemiparesis: Having affected the upper and lower extremity of the same side. The severity of the upper extremity is usually more. Prolonged birth, prematurity and birth asphyxia may play a role in newborns. Infections and traumas such as convulsions, meningitis, encephalitis during the early infancy and childhood may cause hemiparesis. Children which are hemiparetic before 3 years of age are generally assessed within CP.

Diparesis, hemiparesis and quadriparesis occur the most at a ratio of $75 \%$ according to the extremity stiffening in CP (Miller 2004, Matthews \& Wilson 1999, Styer-Acevedo, 1999).

Recently, the clinical type of CP of children with CP is classified based on the most frequent neurologic indications. SCPE's (Surveillance CP Europe) classification system is progressing on creating an international language. According to the record system that SCPE suggests, CP;

Spastic type CP is characterised by at least two:

- Abnormal posture and/or movement.

- Increased tonus (not required to be constant).

- Pathological reflexes (increase in reflexes: hyperreflexia and/or pyramidal indications, i.e. Babinski response).

Spastic CP can be bilateral or unilateral.

Spastic Bilateral CP is diagnosed if it includes extremities on both sides of the body.

Spastic Unilateral CP is diagnosed if it includes extremities on one side of the body.

Ataxic type $\mathrm{CP}$ is characterised both of the below:

- Abnormal posture and/or movement.

- Loss of muscle control so that movements are performed with abnormal force, rhythm and accuracy

Both of the below are dominant in dyskinetic type of $\mathrm{CP}$ :

- Abnormal posture and/or movement.

- Involuntary, incontrollable, repetitive and sometimes stereotype movements. 
Dyskinetic CP however, can by dystonic or choreo-athetoic:

Dystonic CP is active in both situations:

- Hypokinesis (decrease in activity, i.e. difficult movement).

- Hypertonia (tonus generally increased).

Choreo-athetodic CP is active in both situations:

- Hypokinesis (decrease in activity, i.e. severe movements).

- Hypertonia (tonus generally increased) (Krägeloh-Mann 2009, Garne et al. 2008).

International classification of functioning, disability and health (ICF), is a classification system that the World Health Organisation, which provides a standard language and conceptual frame to define health and health related situations, encourages using. The significant classification in recent years has been put forward by the International Classification of Functioning, Disability and Health (ICF) (Rosenbaum \& Stewart, 2007). The complex relationship between disability, participation and environment represents an area of specific importance for children in the rehabilitation professions. The revised version of the ICF, disability and health incorporate biological and social perspectives on disablement, so as to represent fully the impact of health on a person's life, including participation in the community (Gunel \& Mutlu, 2007). Sufficient and appropriate assessment tools are required in order to reveal the activity and participation limitations in paediatric rehabilitation. The ICF model functionality presents an appropriate solution method for those who want to increase the activity and participation of children at the risk level and prevent secondary disorders. Models regarding functionality and health condition constitute the foundation of training and research in clinical practices. The World Health Organisation (WHO) developed the "International Classification of Function, Disability and Health", known as the ICF, in order to record and organise comprehensive information on health and health related issues. Besides health, the ICF was aimed to be used in many fields such as creating policies regarding education, insurance, social security, human rights, work safety, health and liberty and obtaining statistics and used to determine the needs under clinical conditions, for the selection of the treatment in specific health conditions, rehabilitation and assessing rehabilitation results. The general purpose of the ICF classification is to create a common, standard language and frame for defining health and health related issues and define health components and certain components (such as education and workforce) regarding wellness. Therefore, the fields that are within the scope of ICF can be considered as health issues and health related issues (Mutlu et al., 2010).

As a result of an assessment conducted by selecting the required of all these assessments, it shall be possible to define the child's need for physiotherapy and rehabilitation, what could be done and the functional contributions of what has been done.

\section{Physiotherapy and rehabilitation}

Rehabilitation approaches of a children with CP are comprehensive, in addition to the medical and surgical applications; physiotherapy, occupational therapy, speech therapy, orthosis and other adaptive equipment, recreational activities, school and education adaptation and psychosocial support, etc. are included in rehabilitation approaches (Helders, 2003). The aim of rehabilitation in children with CP are; to minimize the effect of physical impairments, to gain independence in the community and to improve the quality of life of the handicapped children and their families who have major roles to play in the process (Cusick, 2006, Schalick, 2001). Rehabilitation in children with CP can differ due to clinical type and severity of table, additional disabilities, physiological age of children, 
socioeconomic factors. In addition visual, auditory, cognitive disorders, seizures, learning disabilities and emotional problems may influence intervention outcomes (Anttila et al., 2008).

Physiotherapy plays a central role in managing the condition; it focuses on function, movement, and optimal use of the child's potential. Physiotherapy uses physical approaches to promote, maintain and restore physical, psychological and social well-being (Damiano, 2008). Children with CP's interventions have lifelong effects, and can be efficient and cost effective (Damiano, 2006). Rehabilitation team members provide services that will help them reach their full potential in their homes and communities. The rehabilitation influence is not restricted to the medical centre and treatment gymnasium, but frequently includes the child's functioning settings within the home, school, recreation, and community environments (Verschuren, 2008).

The physiotherapist focuses on gross motor skills and functional mobility in the management for the motor deficits in CP. Positioning, sitting, transition from sitting to standing, walking with or without assistive devices and orthoses, wheelchair use and transfers, are areas that the physiotherapist works on. In most settings the physiotherapist performs therapy, plans the home program, provides the interphase with the school and recommends equipment (Butler \& Darrah 2001, Yigit et al., 2002).

Physiotherapists emphasize the need for the practice to be evidence-based whenever possible (Kunz 2006). Recently, reviews have addressed the effectiveness of physiotherapy interventions for children with CP focusing on neuro-developmental therapy (NDT) (Msall \& Park 2008), strength training (Dagenais, 2009), conductive education (Bourke-Taylor 2007), various physiotherapy interventions (Tsorlakis et al. 2004), and orthotic management (Morris, 2002). Methods such as biofeedback and electrical stimulation, behavioural and educational approaches such as conductive education, were not included as physiotherapies but were accepted as an adjunct therapy (Colborne et al., 1994, Kerr et al., 2004).

Today, the Bobath approach, initially, aims to observe the existing performance of the child with $\mathrm{CP}$, analyse it, interpret it and then enable the child to reach the maximum level of independency within the limitations of the child's potential assessment and result (DeGangi \& Royeen, 1994). NGT was developed by Bertha Bobath, physiotherapist, Karel Bobath, neuropsychiatrist. At the beginning of the 1940's, Bertha Bobath combined clinical observation, neural maturation theory, hierarchic foundation and reflex development. Bobath's approach was shaped in order to involve scientific theories that were and empirical experiments that were developed and has a structure that is open to development and is dynamic. Thus, it has been developed until our day since its first application and has undergone some changes. According to the Bobath's, the motor problem is one of the most important problems and delay or disorder of normal motor development or not being able to establish postural control against gravity due to function problems in the central nervous system is the most significant factor that causes motor problems (Bly, 1991, Tsorlakis, 2004). In the 1970's, normal motor development started to be experienced, the use of key point was brought to the agenda, and approach of passive and static treatment among physiotherapists was decreased and the concept of simulation became prominent. It was seen during these years that one-on-one communication, normal postural reactions and automatic movement reactions were facilitated, more developed and functional steps of normal motor development were introduced and accurate ambulation was ensured during every phase of motor development. In the 1980's, organisation of daily life activities, positioning during the day, using assisting tools and equipment, using support points, 
enabling correct sitting, carrying, transfer positions, developing sense integration, increasing function of upper extremities and hand and ensuring hand-eye coordination principles came into prominence. From the 1990's to our day, however, active dynamic treatment, training in activities to ensure functionality, developing coordination of the movement and balance, training on telescoped different activities within an action flow have gained significance. Today we see that the expression of tonus coordination is used instead of tonus inhibition and Tonus coordinating patterns (TIP) are used instead of RIP. Positioning that are tonus coordinating and aimed at revealing active movement and simulators that increase sensory-motor activity are used. One other significant development is the key point concept. It has been indicated that use of distal (such as hands, feet) and small body parts, while using key points in order to facilitate the movements, may increase the tonus and that it is better to use larger parts of the body (such as arm, forearm, legs) for facilitation of the movements. The general target is to ensure normal motor development and function and prevent contracture and deformities. The NDT method, which regards all problems occurring in the child as a result of the injury in the central nervous system, has focused on working on memory, perception, sense, postural control and abnormal patterns, reflexes and sensory motor components in the muscle tonus. It is used to facilitate special gripping techniques movement patterns, balance responses and normal muscle tonus and also to decrease abnormal movement patterns, reflexes and spasticity. During the years when the NDT was first developed, the child was more passive in this approach; however, as it has received the name of "living concept" it is observed that the child is more active now (Livanelioglu \& Kerem Gunel 2009, Kerem Gunel, 2009).

The effect of the family is very important and the family must act like a part of the rehabilitation team within the scope of NDT (Butler \& Darrah, 2001). There have been debates on whether NDT principles affect motor development in terms of reflex and hierarchic model of motor control is focused on only neural explanation. For instance, in the motor control model, the central nervous system is regarded as one of the systems that affect only motor behaviour. Motor control is also affected by cognitive and environmental factors. However, physiological components and environmental contents are accepted as non-neural explanations in the child's progress (Fetters \& Kluzik, 1996).

Implementing clinical practices with applications based on evidence is increasingly becoming more important today. Although NDT is the most commonly used method in child rehabilitation by physiotherapists all over the world, research that presents its effects are deemed to be insufficient. There are many reasons for this. Research presenting NDT's effect was organised by AACPDM (American Cerebral Palsy Association) and as a result the difficulties and the evidence encountered were studied (Butler \& Darrah, 2001).

The most prominent difficulty is that all problems, diagnosed on research that includes low incidence and high heterogeneity conditions, become complex with the change of children along with their growth and development process. Despite these obstacles, due to different practices and understandings in applying NDT and its ongoing and wide effect in CP treatment, it is important to collect information on NDT. Researchers indicate that NDT is clinically significant but that no statistical assessment can exactly present its result, partially due to the difficulties mentioned above (24). In researches where the NDT's clinical effect is attempted to be presented by practice, the NDT structure changes with time and in these researches NDT practices are usually performed with other therapy techniques and medical treatments. NDT's effect has been mostly researched in studies in which it is applied together with other rehabilitation practices such as orthesis application, Johonstone Pressure 
Splint, occupational therapy, game therapy, electrical simulation, horse therapy and practices in water (Kerem \& Livanelioglu, 2001, Law, 1997). The primary target of NDT is to change the central nervous system's neural based motor responses. Various aspects of the motor response have been assessed with measurement methods used in conducted researches. These are qualitative movement or physiological motor function (i.e. involuntary muscle tonus changes, spasticity, etc), reflex activity, weight transfer, postural control, trunk rotation, combined reactions, upper extremity movements and walking parameters. As a result of these researches, generally, it has been indicated that a better motor response occurred and that there were positive changes in terms of physiological motor function, movement time, step length for walking, speed and foot angle after the NDT practices (Bobath, 1971). Nonetheless, the evidence of this development in physiological motor functions and qualitative movement is not consistent $(26,31)$. One other very important target of NDT is to prevent or slow down deformities. The measurements of articular movement width, orthesis or surgical suggestions after the NDT practice are used for researching the degree of contractures. It has been indicated that NDT provides advantages in protecting the dynamic articular movement width in the ankle and knee (Kluzik et al. 1990). In other words, when the articular limitation was repetitively and immediately assessed after 20-25 minute NDT sessions, it decreased further. To decrease spasticity, provide normal movement experience, support functional independence during daily activities and thus indirectly support motor learning, physiotherapists use special grips and positioning within the scope of NDT. Dynamic articular movements and the child's active participation during the movement can be clinically descriptive. Motor development: standard tests have been designed for the sample activities in the field of special development; the development is compared to the normal, whereby developmental gain or age is effective. The other fields in the child's development and function and physical and physiological development in developmental theory are interrelated. Therefore, other fields of development can change when abnormal motor behaviour changes through the practice. Although NGT is said to be advantageous in cognitive, lingual, social or emotional fields for physiotherapists and families, this has not yet been statistically indicated in researches (Herndon et al., 1987, Mayston, 2008, Butler \& Darrah, 2001).

Functional limitation and activity participation in practices conducted on children with $\mathrm{CP}$ is one of the main issues researched within the scope of "International Classification of Functioning, Disability and Health (ICF)". The standard tests used for this matter comprise activity or skill attainment items and accept developmental retardation and developmental ages as independent variables and aims to measure functional limitation/activity length and widely-used functional activities such as sitting, walking, dressing-up, playing and communicating with other people. In a study conducted on this topic, it has been proved that NGT increases the gross motor function; however, this study has not entirely put the developmental acquisition (Østensjø, 2006). It supports the expectation regarding NGT's making a greater contribution to the communication between the family and the child. Although it has been shown that in a NGT group mother sensitivity towards child is statistically significant, this effect could not be exactly presented in other groups. When considering principles of evidence-based practices in studies, it is possible to mention that the studies were conducted with groups that have low-level work force and insufficient number of cases and are heterogeneous. When the results are considered, it can be emphasized that NDT practices have positive results on postural tonus, functional independency and dynamic articular movements; however, NDT cannot be proved to be 
superior to other practices and further studies are strongly required. These efforts should involve randomized studies in more comprehensive groups whereby only NDT is applied in homogeneous groups by making use of reliable and valid evaluation analyses where age, sex, severity and type of disease, socio-economic and cultural structure of family are kept under control and which indicate long-term effects.

Exercises refer to planned structured activities involving repeated movement of skeletal muscles that result in energy expenditure and seeks to improve or maintain levels of physical fitness above the intensity of activities of daily living. Several types of therapeutic exercises utilize for improving the child's motor ability as below;

Passive stretching, done manually offered in most spastic children to soft tissue tightness. Manual stretching may support increasing range of movements, reducing spasticity, or improving walking efficiency in children with spasticity. Sustained stretching of longer duration is preferable in improving range of movements and reducing spasticity of muscles around the targeted joints (Arpino et al., 2010). Static weight-bearing exercises are commonly used in order to stimulate antigravity muscle strength, prevent hip dislocation, improve bone mineral density, improve self-esteem, improve feeding, reduce spasticity, and improve fine motor function (Pin, 2007). Strength training aims to increase the power of weak antagonist muscles and the corresponding spastic agonists and provide the functional benefits of strengthening in children with CP (Damiano, 1995). Functional exercises is combining aerobic and anaerobic capacity and strength training, in ambulatory children significantly improved physical fitness, the intensity of activities, and quality of life. Training programs on static bicycles or treadmills were beneficial for gait and gross motor development without enhancing spasticity and abnormal movement patterns (MacPhail \& Kramer, 1995). Electrical stimulation is proposed as a useful modality in CP due to the lack of selective muscle control required for specific strengthening programs. Neuromuscular electrical stimulation and threshold electrical stimulation are used for strengthening the quadriceps muscles in ambulatory children with diplegia who find resistive strengthening programs difficult (Kerr et al., 2004).

\section{Conclusion}

In physiotherapy applications of the children with $\mathrm{CP}$, use the terminology "treatment" only is insufficient. Instead of this terminology, it is more accurate to use "management". Because, physiotherapy of children with CP not only includes the treatment of the motor problems, but also takes all of the requirements of the child and a good family-child relation into consideration. During the applications, existing problems of the child should be taught as a whole of motor, cognitive, sensorial, emotional, social areas. It is very important to determine the realistic goals. The rehabilitation team should determine the short and long term targets according to the existing condition of the child and the team should control the targets in certain periods whether if they can reach those targets. If an unreal target is noticed, providing a correct connection between the condition of the child and the target and planning the strategies to reach the targets are the main principles. During the applications, planning all day, working with the family, integration to daily living activities, helping to the child, increasing the quality of life are important. Determination of the main targets during the treatment, taking the child's personal characteristics into consideration, providing the usage of the functional abilities of child during playing are the other important main points. 


\section{Acknowledgement}

My former colleagues from The Hacettepe University, the Faculty of Health Sciences, The Department of Physiotherapy and Rehabilitation supported me in my all working area. I want to thank them for all their help, support, interest and valuable hints. Especially I am obliged to Ayşe Livanelioğlu, Akmer Mutlu and Özgün Kaya Kara. Especially, I would like to give my special thanks to my husband Hakan Günel whose patient love enabled me to complete this work. Also I want to thank to all children with Cerebral palsy and their families.

\section{References}

Ahl, LE., Johansson, E., Granat, T., Carlberg, EB. (2005). Functional therapy for children with cerebral palsy: an ecological approach. Dev Med Child Neurol, Vol. 47, No. 9, (Sept 2005), pp. (613-619), 0012-1622.

Aicardi, J., Bax, M. (1998). Cerebral palsy, In: Diseases of the Nervous System in Childhood, Jean Aicardi, pp. (210-240), Mac Keith Press, 189868316 6, London.

Akbayrak, T., Armutlu, K., Kerem Gunel, M., Nurlu, G. (2005). Assessment of the short-term effect of antispastic positioning on spasticity. Pediatrics International, Vol. 47, No.4, (August 2005), pp. (440-445), 1328-8067.

Albright, A. (1996). Spasticity and movement disorders in cerebral palsy. J Child Neurol, Vol. 11, No. Suppl 1, (Nov 1996), pp. (1-4), 0883-0738.

Anttila, H., Autti-Rämö, I., Suoranta, J., Mäkelä, M. et al. (2008). Effectiveness of physical therapy interventions for children with cerebral palsy: a systematic review. BMC Pediatr, Vol.24, No.8, (Apr 2008), pp. (14), 1471-2431.

Anttila, H., Suoranta, J., Malmivaara, A., Mäkelä, M., Autti-Rämö, I. (2008). Effectiveness of physiotherapy and conductive education interventions in children with cerebral palsy: a focused review. Am J Phys Med Rehabil, Vol.87, No.6, (Jun 2008), pp. (478501), 0894-9115.

Arpino, C., Vescio, MF., De Luca, A., Curatolo, P. (2010). Efficacy of intensive versus nonintensive physiotherapy in children with cerebral palsy: a meta-analysis. Int $J$ Rehabil Res, Vol.33, No.2, (Jun 2010), pp. (165-171), 0342-5282.

Bax, M., Goldstein, M., Rosenbaum, P., Leviton, A., Paneth, N., Jacobsson, B., Damiano, DL. (2005). Proposed definition and classification of cerebral palsy. Dev Med Child Neurol, Vol.47, No.8, (Aug 2005), pp. (571-576), 0012-1622.

Berger, W. (1998). Characteristics of locomotor control in children with cerebral palsy. Neurosci Biobehav Rev, Vol. 22, No.4, (Jul 1998), pp. (579-582), 0149-7634.

Bly, L. (1991). A historical and current view of the basis of NDT. Pediatric Physical Therapy, Vol.3, No. 3, pp. (131-135), 0898-5669.

Bobath, K., Bobath, B. (1984). The neuro-developmental treatment, In: Management of the Motor Disorders of Children with Cerebral Palsy, David Scrutton, Dianne Damiano, Margaret Mayston, pp. (6-18), JB Lippincott, Philadephia.

Bobath, K. (1971). The normal postural reflect mechanism and its deviation in children with cerebral palsy. Physiotherapy, Vol.57, No.11, (Nov 1971), pp. (526-532), 0031-9406. 
Bourke-Taylor, H., O'Shea, R., Gaebler-Spira, D. (2007). Conductive education: a functional skills program for children with cerebral palsy. Phys Occup Ther Pediatr, Vol.27, No.1, pp. (45- 62), 0194-2638.

Bower, E., McLellan, DL. (1992). Effect of increased exposure to physiotherapy on skill acquisition of children with cerebral palsy. Dev Med Child Neurol, Vol.34, No.1, (Jan 1992), pp. (25-39), 0012-1622.

Butler, C., Chambers, H., Goldstein, M. (1999). Evaluating research in developmental disabilities: a conceptual framework for reviewing treatment outcomes. Dev Med Child Neurol, Vol. 41, No. 1, (Jan 1999), pp. (55-59), 0012-1622.

Butler, C., Darrah, J. (2001). AACPDM Evidence report: Effects of neurodevelopmental treatment (NDT) for cerebral palsy. Dev Med Child Neurol, Vol.43, No.11, (Nov 2001), pp. (778-790), 0012-1622.

Colborne, GR., Wright, FV., Naumann, S. (1994). Feedback of triceps surae EMG in gait of children with cerebral palsy: a controlled study. Arch Phys Med Rehabil, Vol. 75, No. 1, (Jan 1994), pp. (40-45), 0003-9993.

Cusick, A., Mcintyre, S., Novak, I., Lannin, N., Lowe, K. (2006). A comparison of goal attainment scaling and the Canadian occupational performance measure for pediatric rehabilitation research. Pediatr Rehabil, Vol. 9, No.2, (Apr-Jun 2006), pp. (149-157), 1363-8491.

Dagenais, LM., Lahay, ER., Stueck, KA., White, E., Williams, L., Harris, SR. (2009). Effects of electrical stimulation, exercise training and motor skills training on strength of children with meningomyelocele: a systematic review. Phys Occup Ther Pediatr, Vol.29, No.4, pp. (445- 463), 0194-2638.

Damiano, DL., Kelly, LE., Vaughan CL. (1995). Effects of a quadriceps femoris strengthening programme on crouch gait in children with cerebral palsy. Phys Ther, Vol.75, No.8, (Aug 1995), pp. (658-667), 0031-9023.

Damiano, DL., Laws, E., Carmines, DV., Abel, MF. (2006). Relationship of spasticity to knee angular velocity and motion during gait in cerebral palsy. Gait Posture, Vol.23, No.1, (Jan 2006), pp. (1-8), 0966-6362.

Damiano, DL., Moreau, N. (2008). Muscle thickness reflects activity in CP but how well does it represent strength? Dev Med Child Neurol, Vol. 50, No.2, (Feb 2008), pp. (88), 00121622.

Damiano, DL. (2006). Activity, activity, activity: rethinking our physical therapy approach to cerebral palsy. Phys Ther, Vol.86, No.11, (Nov 2006), pp. (1534-1540), 0031-9023.

De Graaf-Peters, VB., Blauw-Hospers, CH., Dirks, T., Bakker, H., Bos, AF., Hadders-Algra, M. (2007). Development of postural control in typically developing children and children with cerebral palsy: possibilities for intervention? Neurosci Biobehav Rev, Vol.31, No.8, (May 2007), pp. (1191-1200), 0149-7634.

DeGangi, G., Royeen, C. (1994). Current practice among neurodevelopmental treatment association members. Am J Occup Ther, Vol.48, No.9, (Sep 1994), pp. (803-809), 02729490 .

Deon, LL., Gaebler-Spira, D. (2010). Assessment and treatment of movement disorders in children with cerebral palsy. Orthop Clin North Am, Vol. 41, No. 4, (Oct 2010), pp. (507-517), 0030-5898. 
Damiano, DL. (2009). Rehabilitative Therapies in Cerebral Palsy: The Good, the Not As Good, and the Possible. J Child Neurol, Vol. 24, No.9,(Sept 2009), pp. (1200-1204), 0883-0738.

Eliasson, AC., Krumlinde-Sundholm, L., Rösblad, B., Beckung, E., et al. (2007). Using the MACS to facilitate communication about manual abilities of children with cerebral palsy. Dev Med Child Neurol, Vol.49, No. 2, (Feb 2007), pp. (156-157), 0012-1622.

Erdoganoglu, Y., Gunel, MK. (2007). Investigation of health-related quality of life of families with have children with cerebral palsy. Bulletin of Community Medicine, Vol.26, No.2, (May-Aug 2007), pp. (35-39), 1300-6061.

Erdoganoglu, Y., Gunel, MK. (2007). Investigation of the relationship between motor and functional levels with health-related quality of life in children with cerebral palsy. Bulletin of Community Medicine, Vol. 26, No. 3, (Sept-Dec 2007), pp. (13-18), 13006061.

Fetters, L., Kluzik, J. (1996). The effects of neurodevelopmental treatment versus practice on the reaching of children with spastic cerebral palsy. Phys Ther, Vol.76, No.4, (Apr 1996), pp. (346-358), 0031-9023.

Gaebler-Spira, D., Revivo, G. (2003). The use of botulinum toxin in pediatric disorders. Phys Med Rehabil Clin N Am, Vol. 14, No.4, (Nov 2003), pp.703-725, 1047-9651.

Gage, JR., Novacheck, TF. (2001). An update on the treatment of gait problems in cerebral palsy. J Pediatr Orthop B, Vol.10, No.4, (Oct 2001), pp. (265-274), 1060-152X.

Garne, E., Dolk, H., Krägeloh-Mann, I., Holst Ravn, S., Cans, C.; SCPE Collaborative Group. (2008). Cerebral palsy and congenital malformations. Eur J Paediatr Neurol, Vol.12, No.2, (Mar 2008), pp. (82-88), 1090-3798.

Graham, HK. (2001). Botulinum toxin type A management of spasticity in the context of orthopaedic surgery for children with spastic cerebral palsy. Eur J Neurol, Vol. 8, No. Suppl 5, (Nov 2001), pp. (30-39), 1351-5101.

Gunel, MK. (2006). Rehabilitation approaches and physiotherapy applications in children with involuntary movement. Turkey Clinics J Pediatr Sci, Vol.2, No.8, pp. (71-75), 1305- 435X.

Gunel, MK., Mutlu, A., Tarsuslu, T., Livanelioglu, A. (2009). Relationship among the Manual Ability Classification System (MACS), the Gross Motor Function Classification System (GMFCS), and the functional status (WeeFIM) in children with spastic cerebral palsy. Eur J Pediatr. Vol.168, No.4, (Apr 2009), pp. (477-485), 0340-6199.

Hadders-Algra, M. (2001). Early brain damage and the development of motor behavior in children: clues for therapeutic intervention? Neural Plast, Vol.8, No.1-2, pp. (31-49), 2090-5904.

Harris, SR., Roxborough, L. (2005). Efficacy and effectiveness of physical therapy in enhancing postural control in children with cerebral palsy. Neural Plast, Vol.12, No.2-3,pp.(229-243), 2090-5904.

Helders, PJM., Raoul, H., Engelbert, H., Custers, JWH., Gorter, JW., Takken, T., Van Der Net, J. (2003). Creating and being created: the changing panorama of pediatric rehabilitation. Pediatr Rehabil, Vol. 6, No. 1, (Jan-Marc 2003), pp. (5-12), 1363-8491. 
Herndon, WA., Troup, P., Yngve, DA., Sullivan, JA. (1987). Effects of neurodevelopmental treatment on movement patterns of children with cerebral palsy. J Pediatr Orthop, Vol.7, No. 4, (Jul-Aug 1987), pp. (395-400), 0271-6798.

Krägeloh-Mann, I., Cans, C. (2009). Cerebral palsy update. Brain Dev, Vol.31, No. 7, (Aug 2009), pp. (537-544), 0387-7604.

Johnson, DA., Rivilin, E., Stein, DG. (2001). Pediatric rehabilitation: improving recovery and outcome in childhood disorders. Pediatr Rehabil, Vol. 4, No.1, (Jan- Mar 2001), pp. (1-3), 1363-8491.

Kerem Gunel, M. (2009). Rehabilitation of children with cerebral palsy from a physiotherapist's perspective. Acta Orthop Traumatol Turc, Vol.43, No.2, (Mar-Apr 2009), pp. (173-181), 1017-995X.

Kerem, M., Livanelioglu, A. (2003). Effects of neurodevelopment therapy on motor development in children with cerebral palsy. Physiotherapy Rehabil, Vol. 13, No. 3, pp. (117-123), 1300-8757.

Kerr, C., McDowell, B., McDonough, S. (2004). Electrical stimulation in cerebral palsy: a review of the effects on strength and motor function. Dev Med Child Neurol, Vol.46, No. 3,(Mar 2004), pp. (205-213), 0012-1622.

Kluzik, J., Fetters, L., Coryell, J. (1990). Quantification of control: a preliminary study of effects of neurodevelopmental treatment on reaching in children with spastic cerebral palsy. Physical Therapy, Vol. 70, No.2: (Feb 1990), pp. (65-76), 0031-9023.

Koman, LA., Paterson Smith, B., Balkrishnan, R. (2003). Spasticity associated with cerebral palsy in children: guidelines for the use of botulinum A toxin. Paediatr Drugs, Vol.5, No.1, pp. (11-23), 1174-5878.

Kunz, R., Autti-Rämö, I., Anttila, H., Malmivaara, A., Mäkelä, M. (2006). A systematic review finds that methodological quality is better than its reputation but can be improved in physiotherapy trials in childhood cerebral palsy. J Clin Epidemiol, Vol.59, No.12, (Dec 2006), pp. (1239-1248), 0895-4356.

Kwolek, A., Majka, M., Pabis, M. (2001). The rehabilitation of children with cerebral palsy: problems and current trends. Ortop Traumatol Rehabil, Vol.3, No.4, pp. (499-507), 1509-3492.

Law, M., Russell, D., Pollock, N., Rosenbaum, P., Walter, S., King, G. (1997). A comparison of intensive neurodevelopmental therapy plus casting and a regular occupational therapy program for children with cerebral palsy. Dev Med Child Neurol, Vol.39, No.10,(Oct 1997), pp.664- 670, 0012-1622.

Livanelioglu, a., Kerem Gunel, M. (2009). Serebral Palside Fizyoterapi, Pp: 61-71,Yeni Özbek Matbbaas1, Ankara, ISBN: 978-605-89077-0-6.

MacPhail, HEA., Kramer, JF. (1995). Effect of isokinetic strengthtraining on functional ability and walking efficiency in adolescents with cerebral palsy. Dev Med Child Neurol, Vol.37, No.9, (Sep 1995), pp. (763-775), 0012-1622.

Matthews, D.J., Wilson, P. (1999). Cerebral Palsy, In: Pediatric Rehabilitation, 3rd ed., G. E. Molnar and M. A. Alexander, pp. (193-217), Hanley \& Belfus, hiladelphia.

Mayston, M. (2008). Bobath Concept: Bobath@50: mid-life crisis--what of the future? Physiother Res Int, Vol.13, No.3, (Sep 2008), pp. (131-136), 1358-2267. 
Mayston, MJ. (2001). People with cerebral palsy: effects of and perspectives for therapy. Neural Plast, Vol.8, No.1-2, pp. (51-69), 2090-5904.

Miller, F. (2004). Etiology, epidemiology, pathology, and diagnosis. In: Cerebral Palsy, Miller F, Springer-Verlag, Inc., New York.

Gunel, MK., Mutlu, A. (2007). Disability and its relation with functional independence in children with cerebral palsy: an ICF study of preliminary clinical experience from Turkey. Physiotherapy Rehabil, Vol. 18, No.3, pp. (171-178), 1300-8757.

Mohay, H. (1996). Focus on the child, Family and Therapist, In: Physiotherapy and the Growing Child, Burns YR, MacDonald J, pp: (3-25), WB Saunders, 0-7020-1942- 9, UK.

Morris, C. (2002). A review of the efficacy of lower-limb orthoses used for cerebral palsy. Dev Med Child Neurol, Vol.44, No.3, (Mar 2002), pp. (205-211), 0012-1622.

Msall, ME., Park, JJ. (2008). Neurodevelopmental management strategies for children with cerebral palsy: optimizing function, promoting participation, and supporting families. Clin Obstet Gynecol, Vol.51, No.4, (Dec 2008), pp. 800-815, 0009-9201.

Mutlu, A., Akmese, PP., Kerem Gunel, M., Karahan, S., Livanelioglu, A. (2010). The importance of motor functional levels from the activity limitation perspective of ICF in children with cerebral palsy. Int J Rehabil Res, Vol.33, No.4, (Dec 2010), pp.319-324, 0342-5282.

Mutlu, A., Livanelioglu, A., Kerem Gunel, M. (2008). Reliability of Ashworth and Modified Ashworth Scales in children with spastic cerebral palsy. BMC Musculoskeletal Disorders, Vol.9, (Apr 2008), pp. (44), 1471-2474.

Mutlu, A., Livanelioglu, A., Kerem Gunel, M. (2007). Reliability of goniometric measurements in children with spastic cerebral palsy. Med Sci Monit, Vol.13, No.7, (Jul 2007), pp.323-329, 1234-1010.

Novacheck, TF., Gage, JR. (2007). Orthopedic management of spasticity in cerebral palsy. Childs Nerv Syst, Vol. 23, No. 9, (Sep 2007), pp. (1015-1031), 0256-7040.

Novacheck, TF., Trost, JP., Sohrweide, S. (2010). Examination of the child with cerebral palsy. Orthop Clin North Am, Vol.41, No.4, (Oct 2010), pp. (469-488), 0030-5898.

Odding, E., Roebroeck, M., Stam, H. (2006). The epidemiology of cerebral palsy: incidence, impairments and risk factors. Disabil Rehabil, Vol. 28, No.4, (Feb 2006), pp.183-191, 0963-8288.

Olney, S., Wright, M. (2000). Cerebral palsy. In: Physical therapy for children, Campbell S, Vander Linden D, Palisano R, pp. (533-571), W.B. Saunders Company, 0-7216-83169, Philadelphia, USA.

O'Shea, TM. (2008). Diagnosis, treatment, and prevention of cerebral palsy. Clin Obstet Gynecol, Vol.51, No.4, (Dec 2008), pp. (816-828), 0009-9201.

Østensjø, S., Bjorbækmo, W., Carlberg, EB., Vøllestad, NK. (2006). Assessment of everyday functioning in young children with disabilities: An ICF-based analysis of concepts and content of the Pediatric Evaluation of Disability Inventory (PEDI). Disabil Rehab, Vol.28, No. 8, (Apr 2006), pp. (489-504), 0963-8288.

Ottenbacher, KJ., Msall, ME., Lyon, N., Duffy, LC., Granger, CV., Braun, S. (1999). Measuring developmental and functional status in children with disabilities. Dev Med Child Neurol, Vol.41, No.3, (Mar 1999), pp. (186-194), 0012-1622. 
Palisano, R., Rosenbaum, P., Walter, S., Russell, D., et al. (1997). Development and reliability of a system to classify gross motor function in children with cerebral palsy. Dev Med Child Neurol, Vol.39, No.4, (Apr 2009), pp. (214-223), 0012-1622.

Papavasiliou, AS. (2009). Management of motor problems in cerebral palsy: a critical update for the clinician. Eur J Paediatr Neurol, Vol. 13, No. 5, (Sep 2009), pp. 387-396, 10903798.

Pin, TW. (2007). Effectiveness of static weight-bearing exercises in children with cerebral palsy. Pediatr Phys Ther, Vol. 19, No. 1, pp. (62-73), 0898-5669.

Rosenbaum, P., Stewart, D. (2007). Perspectives on transitions: rethinking services for children and youth with developmental disabilities. Arch Phys Med Rehabil, Vol.88, No.8, pp. (1080-1082), 0003-9993.

Russell, DJ., Avery, LM., Rosenbaum, PL., Raina, PS., Walter, SD., Palisano, RJ. (2000). Improved scaling of the gross motor function measure for children with cerebral palsy: evidence of reliability and validity. Phys Ther, Vol.80, No. 9, (Sep 2000), pp. (873-885), 0031-9023.

Russell, DJ., Rosenbaum, PL., Cadman, DT., Gowland, C., et al. (1989). The Gross Motor Function Measure: a means to evaluate the effects of physical therapy. Dev Med Child Neurol, Vol.31, No. 3, (Jun 1989), pp. (341-352), 0012-1622.

Schalick, WO. (2000). Children, disability and rehabilitation in history. Pediatr Rehabil, Vol. 4, No. 2, (Apr-Jun 2000), pp. (91-95), 1363-8491.

Schanzenbacher, KE. (1989). Diagnostic problems in pediatrics, In: Occupational Therapy for Children, Pratt PN, St Allen AS, pp. (97), Mosby', Toronto.

Shepherd, R. (1995). Cerebral palsy, In: Physiotherapy in pediatrics, Shepherd R, pp. (110-144), Oxford, 075060620 7, Butterworth-Heinemann.

Stanger, M. Oresic, S. (2003). Rehabilitation approaches for children with cerebral palsy: overview. J Child Neurol, Vol.18, No. Suppl 1, (Sep 2003), pp. S79-88, 0883-0738.

Stanley, F., Blair, E., Alberma, E. (2000). In: Cerebral palsies: epidemiology and causal pathways, pp. (151), MacKeith Press, 189868320 4, London

Styer-Acevedo, J. (1999). Physical Therapy for the Child with Cerebral Palsy, In: Pediatric Physical Therapy, 3rd ed., J. S. Tecklin, pp. (107-162), Lippincott Williams \& Wilkins, 0-7817-5399-6, Philadelphia.

Tirosh, E., Rabino, S. (1989). Physiotherapy for children with cerebral palsy. Evidence for its efficacy. Am J Dis Child. Vol.143, No.5, (May 1989), pp:552-555, 0002-922X.

Tsorlakis, N., Evaggelinou, C., Grouios, G., Tsorbatzoudis, C. (2004). Effect of intensive neurodevelopmental treatment in gross motor function of children with cerebral palsy. Dev Med Child Neurol, Vol.46, No. 11, (Nov 2004), pp. (740-745), 0012-1622.

Verschuren, O., Ketelaar, M., Takken, T., Helders, PJ., Gorter, JW. (2008). Exercise programs for children with cerebral palsy: a systematic review of the literature. Am J Phys Med Rehabil, Vol. 87, No. 5, (May 2008), pp. (404-417), 0894-9115.

Vos-Vromans, DC., Ketelaar, M., Gorter, JW. (2005). Responsiveness of evaluative measures for children with cerebral palsy: the Gross Motor Function Measure and the Pediatric Evaluation of Disability Inventory. Disabil Rehabil, Vol. 27, No.20, (Oct 2005), pp. (1245-1252), 0963-8288. 
Yigit, S., Kerem, M., Livanelioglu, A., Oran, O., Erdem, G., Mutlu, A., Turanlı, G., Tekinalp, G., Yurdakok, M. (2002). Early Physiotherapy intervention in premature infants. Turk J Pediatr, Vol.44, No. 3, (Jul-Sep 2002), pp. (224-229), 0041-4301. 


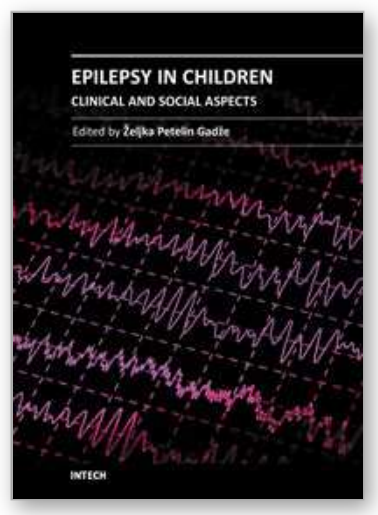

\author{
Epilepsy in Children - Clinical and Social Aspects \\ Edited by Dr. Zeljka Petelin Gadze
}

ISBN 978-953-307-681-2

Hard cover, 234 pages

Publisher InTech

Published online 15, September, 2011

Published in print edition September, 2011

Epilepsy is a neurological condition that accompanies mankind probably since its inception. About 400 years before Christ, the disease was already known by Hippocrates, who wrote the book â€œOn The Sacred Diseaseâ€. Classically, epilepsy has been defined as a chronic condition characterized by an enduring propensity to generate seizures, which are paroxysmal occurring episodes of abnormal excessive or synchronous neuronal activity in the brain. Out of all brain disorders, epilepsy is the one that offers a unique opportunity to understand normal brain functions as derived from excessive dysfunction of neuronal circuits, because the symptoms of epileptic seizures are not the result of usual loss of function that accompanies many disease that affect the brain. I am therefore extremely honoured to present this book. The 15 very interesting chapters of the book cover various fields in epileptology â $€$ " they encompass the etiology and pathogenesis of the disease, clinical presentation with special attention to the epileptic syndromes of childhood, principles of medical management, surgical approaches, as well as social aspects of the disease.

\title{
How to reference
}

In order to correctly reference this scholarly work, feel free to copy and paste the following:

Mintaze Kerem Günel (2011). Physiotherapy for Children with Cerebral Palsy, Epilepsy in Children - Clinical and Social Aspects, Dr. Zeljka Petelin Gadze (Ed.), ISBN: 978-953-307-681-2, InTech, Available from:

http://www.intechopen.com/books/epilepsy-in-children-clinical-and-social-aspects/physiotherapy-for-childrenwith-cerebral-palsy

\section{INTECH}

open science | open minds

\section{InTech Europe}

University Campus STeP Ri

Slavka Krautzeka 83/A

51000 Rijeka, Croatia

Phone: +385 (51) 770447

Fax: +385 (51) 686166

www.intechopen.com

\section{InTech China}

Unit 405, Office Block, Hotel Equatorial Shanghai

No.65, Yan An Road (West), Shanghai, 200040, China

中国上海市延安西路65号上海国际贵都大饭店办公楼405单元

Phone: +86-21-62489820

Fax: $+86-21-62489821$ 
(C) 2011 The Author(s). Licensee IntechOpen. This chapter is distributed under the terms of the Creative Commons Attribution-NonCommercialShareAlike-3.0 License, which permits use, distribution and reproduction for non-commercial purposes, provided the original is properly cited and derivative works building on this content are distributed under the same license. 